\title{
Experimental Investigation on OSB Webbed Laminated Bamboo Lumber Box Shaped Joists
}

\author{
Chang Liu, Guo Chen*, Lingyu Li, Yu Qin, Jiayi Wang, Minghan Xu \\ College of Civil Engineering, Nanjing Forestry University, Nanjing 210037, China
}

\begin{abstract}
A novel bamboo-wood box beam was introduced in this paper, which consisted of laminated bamboo lumber flanges and OSB webs. Four-point bending tests were conducted on composite beams to investigate the effects of shear span ratio and stiffeners on failure mode and strength. The results showed that the composite beams with shear span ratio less than two failed in web shear failure, but for the others, the beams failed in twist and delamination of OSB in flanges. The load carrying capacity of beams decreased with the increase of shear span ratio. However, the mechanical performance of beams can be improved moderately by the presence of stiffeners, and theultimate bearing capacity and initial stiffness was increased by $16.5 \%$ and $13.1 \%$ respectively.
\end{abstract}

\section{Introduction}

In recent years, the high quality wood with large diameter worldwide has been decreasing year by year, resulting in the application of wood structure was limited seriously [1-4]. China is rich in bamboo resources and has a long history in utilizing bamboo. As a sustainable green building materials, increasing attention has been paid on the application of bamboo which is considered as an alternative to wood [5-6]. Recently, laminated bamboo lumber (LBL) has been manufactured by peeling bamboo culms to $4-5 \mathrm{~mm}$ thickness and 6-8 $\mathrm{mm}$ width strips and gluing them together with phenol formaldehyde resin, which overcomes the disadvantages of raw bamboo, such as thin-walled hollow and easy to crack when exposed to humid air [7-10].

Wood I joists are efficient and lightweight structural members that are widely used as floor and roof joists in residential buildings for decades [11-14]. However, because of the relatively stiffness and strength of flanges, the flanges of the joists are prone to fracture suddenly and exhibit brittle failure characteristic. To address these issues, steel plates and FRP sheet were usually used to paste on the bottom of joists, but the improvement on strength and stiffness was limited [15-17].

Therefore, OSB webbed laminated bamboo lumber box shaped joists are introduced, which can be used as an alternative to wood I joists. The objective of this study was to investigate the strength and deformation of composite box joists. The experimental results obtained can provide useful reference for the design and application of box joists.

\section{Materials and methods}

\footnotetext{
* Corresponding author: chenguo@njfu.edu.cn
}

Prefabricated OSB webbed laminated bamboo lumber box shaped joists consisted of four components: a flange material, a web material, an adhesive and nails. The LBL flanges, $30 \mathrm{~mm} \times 35 \mathrm{~mm}$ in dimension, were provide by Dongguan Xiangnan Bamboo Industry Co. Ltd. And the OSB webs typically was $9.5 \mathrm{~mm}$ in thickness [18-19]. The two component epoxy resin structural adhesive (Yijiayi New Material Technology Co., Ltd., Yancheng, China) cured at room temperature was used for flangeweb connections. The consumption of adhesive is 250 $\mathrm{g} / \mathrm{m}^{2}$. Then smooth nails $(2.8 \mathrm{~mm} \times 40 \mathrm{~mm})$ with 150 $\mathrm{mm}$ spacing were directly nailed into bamboo flanges from the side of the OSB plates. To avoid splitting of bamboo flanges occurred, the minimum edge distance of nails was $10 \mathrm{~mm}$. The finished specimens were stored in the lab at $20{ }^{\circ} \mathrm{C} \pm 2{ }^{\circ} \mathrm{C}$ and $65 \% \pm 5 \%$ relative humidity for two weeks.

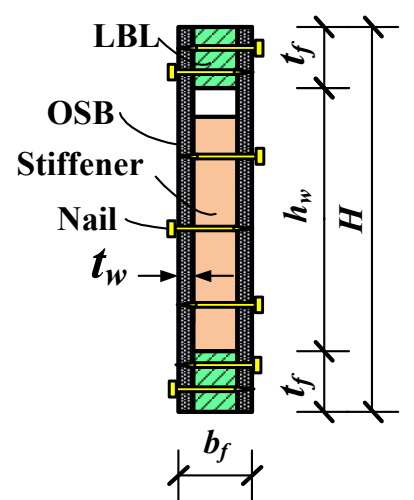

Fig. 1. Cross-section of specimen.

The experimental program comprised tests on 12 specimens, which were grouped into 2 series. The properties of composite joists, such as shear span ratio and stiffeners are presented in Table 1. All the specimens were $240 \mathrm{~mm}$ in height, $2.44 \mathrm{~m}$ in length and $49 \mathrm{~mm}$ in 
width. The shear span ratio $\left(\lambda=l_{1} / L\right)$ was $1.2,1.4,1.6,1.8$, 2.0 and 2.5 for WB1-WB6 respectively. To investigate the effect of stiffeners on the mechanical performance of composite joists, stiffeners $(30 \mathrm{~mm} \times 35 \mathrm{~mm} \times 227 \mathrm{~mm})$ were required at the two supports and also at points of concentrated loads for specimens (WB7-WB12). Install bearing stiffeners tight against the bottom flange of the Ijoist, leaving $5 \mathrm{~mm}$ gap at the top. But the load stiffeners had the opposite installation (Fig. 1).

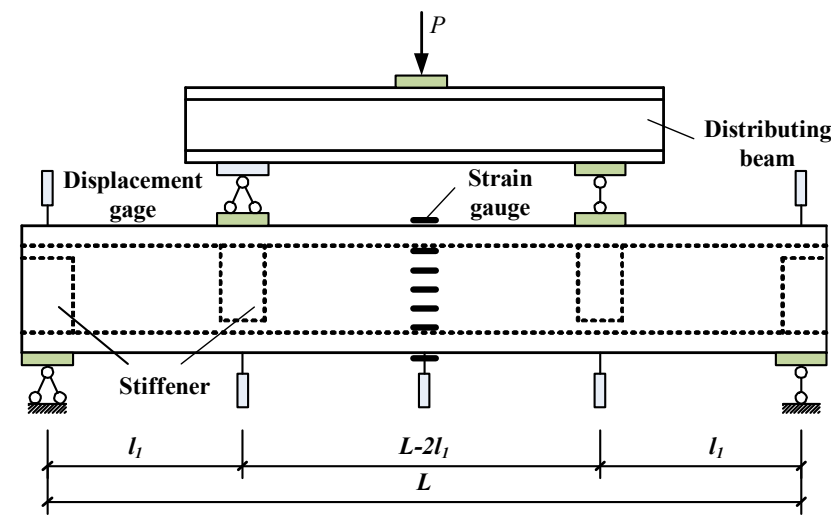

Fig. 2. Test set-up.

Table 1. Details of specimen parameters.

\begin{tabular}{|c|c|c|c|c|}
\hline Specimens & $\boldsymbol{b}_{\mathbf{f}} \times \boldsymbol{t}_{\mathbf{t}} / \mathbf{m m}$ & $\boldsymbol{l}_{\mathbf{1}} \mathbf{m} \boldsymbol{m}$ & $\boldsymbol{\lambda}$ & Stiffener \\
\hline WB1 & $49 \times 35$ & 360 & 1.2 & No \\
\hline WB2 & $49 \times 35$ & 420 & 1.4 & No \\
\hline WB3 & $49 \times 35$ & 480 & 1.6 & No \\
\hline WB4 & $49 \times 35$ & 540 & 1.8 & No \\
\hline WB5 & $49 \times 35$ & 600 & 2.0 & No \\
\hline WB6 & $49 \times 35$ & 750 & 2.5 & No \\
\hline WB7 & $49 \times 35$ & 360 & 1.2 & Yes \\
\hline WB8 & $49 \times 35$ & 420 & 1.4 & Yes \\
\hline WB9 & $49 \times 35$ & 480 & 1.6 & Yes \\
\hline WB10 & $49 \times 35$ & 540 & 1.8 & Yes \\
\hline WB11 & $49 \times 35$ & 600 & 2.0 & Yes \\
\hline WB12 & $49 \times 35$ & 750 & 2.5 & Yes \\
\hline
\end{tabular}

Four-point bending experiments on the specimens were conducted under monotonic loading condition. The testing apparatus is shown in Fig. 2. Vertical loading was applied using an Electro hydraulic servo loading system with a 500-mm stroke. The actuator was connected through another rectangular steel distributing beam to the top flange of the specimens. A total of seven instruments was installed on each joist to record the midspan displacement, the applied force, the settlement of the two supports and the mid-span strains along beam depth. The testing was displacement-controlled until failure and the loading rates were $2 \mathrm{~mm} / \mathrm{min}$, according to the ASTM D5055 (2010). All the data were collected by a data acquisition system and the sampling frequency was $1 \mathrm{HZ}$.

\section{Results and discussion}

\subsection{Observed behavior and failure modes}

The load-deflection curves for specimens with and without stiffeners were shown in Fig. 3. It was clear that the specimens behaved elastically up to ultimate load, followed by an abrupt drop in load carrying capacity. The present of stiffeners had positive effect on the mechanical performance of joists. At the initial stage of loading, the mid-span deflection of specimens increased linearly with increasing applied loading, and small cracking noise of wood could be heard. However, no visual damage of flanges and webs were observed until reaching to ultimate bearing capacity. Once the joists reached the ultimate strength, the joists soon lost suddenly and damage normally happened without any obvious symptom, exhibiting brittle failure characteristic.

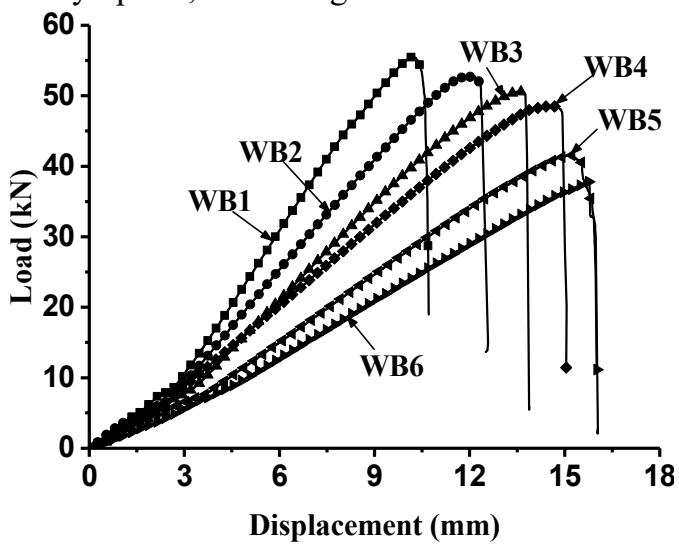

(a) B1-B6

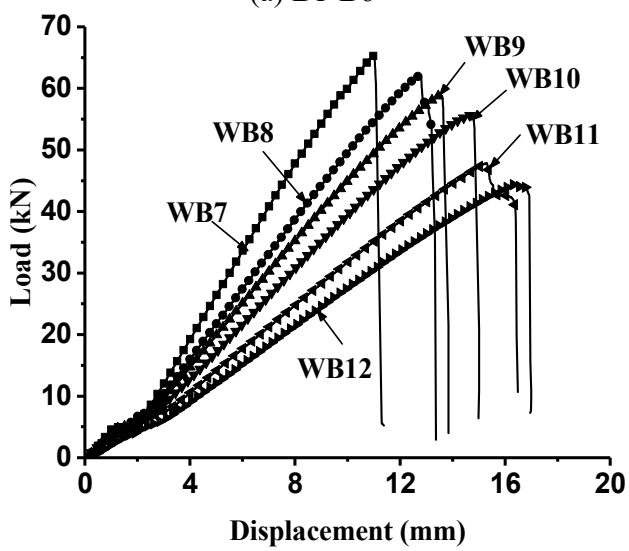

(b) BI7-B12

Fig. 3. Load- displacement curves.

Observed failure modes in specimens were different depending on the shear span ratio and stiffeners. Three typical failure modes were recorded, including web shear failure, local web buckling and delamination of OSB from flanges. As shown in Fig. 4(a), tested specimens with shear span ratio less than two, web shear failure was recorded at the mid-span of the joists. The graph in Fig. 4(b) illustrated the local web buckling for specimens without stiffeners. Nonetheless, failures in which the nails pulled through the OSB panels or fracture occurred, but was seldom investigated. When reaching to 50 percent of the ultimate load, the specimens with shear span ratio more than two began to twist and sawdust dropped from the web-flange connection. Although no visual damage could be observed at this moment, it was clear that the connections were damaged slightly. As shown in Fig. 4(c), once the joists reached the ultimate strength, the OSB separated from the flanges suddenly and nails were pulled out or sheared off. Surprisingly, unlike the sudden fracture flange failures of the wood 
joist $[13,17]$, the LBL flanges of composite joists in this study remained intact, which was extremely important to protect dwellers from injury or damage.

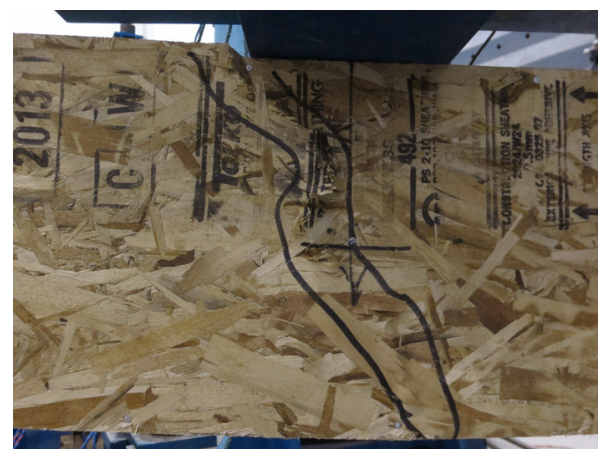

(a) web shear failure

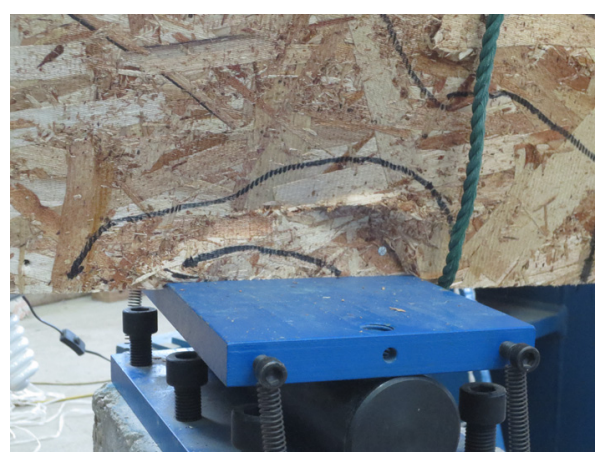

(b) Local buckling

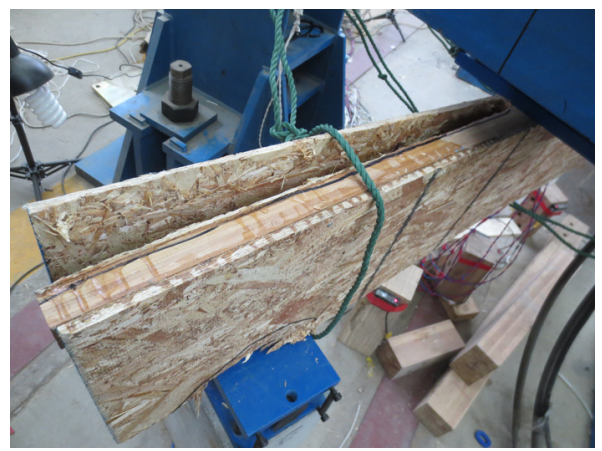

(c) Delamination of OSB in flanges

Fig. 4. Typical failure modes.

\subsection{Strength and bending stiffness}

It was showed that the strength of composite joists affected by the considered variables in the tests. The main test results of the specimens were presented in Table 2. Observed results revealed that the shear span ratio affected the strength of the joists, and the strength decreased with increasing shear span ratio. However, the effect of the stiffeners has more significant influence on the capacity of specimens than that of the shear span ratio. The local buckling performance of the web could be improved by the stiffeners, therefore, the load carrying capacity and displacement corresponding to ultimate load of specimens was significantly increased by about $16.5 \%$ and $3.6 \%$ respectively. According to the current Chinese code for design of timber structures (GB 50005-2003), the mid-span deflection of the wood beam at serviceability limit states shall not exceed L/250, that is, the deflection limit of specimen in this study was 8 $\mathrm{mm}$. Usually, the bearing capacity of wood I joists and bamboo beams at the serviceability limit state was only $30 \%$ of the ultimate limit states [15, 20-22]. However, for OSB webbed bamboo box shaped joists, the relative ratio was about $60 \%$. Of course, the composite beam in my research was controlled by stiffness rather than strength.

Table.2 Experimental results

\begin{tabular}{|c|c|c|c|c|}
\hline Specimens & $P_{c r}(\mathrm{kN})$ & $P_{u}(\mathrm{kN})$ & $\begin{array}{c}P_{L / 250} \\
(\mathrm{kN})\end{array}$ & $D_{u}(\mathrm{~mm})$ \\
\hline WB1 & 23.77 & 55.53 & 44.41 & 10.21 \\
\hline WB2 & 21.48 & 52.79 & 35.83 & 12.14 \\
\hline WB3 & 20.23 & 50.58 & 30.34 & 13.60 \\
\hline WB4 & 19.85 & 48.53 & 27.88 & 14.51 \\
\hline WB5 & 18.72 & 41.55 & 21.42 & 15.12 \\
\hline WB6 & 16.71 & 37.81 & 18.25 & 15.74 \\
\hline WB7 & 33.64 & 65.28 & 47.76 & 10.98 \\
\hline WB8 & 30.08 & 62.12 & 38.73 & 12.73 \\
\hline WB9 & 28.47 & 58.86 & 35.24 & 14.02 \\
\hline WB10 & 27.86 & 55.67 & 30.72 & 14.72 \\
\hline WB11 & 22.91 & 47.84 & 24.75 & 15.38 \\
\hline WB12 & 21.20 & 44.74 & 21.47 & 16.44 \\
\hline
\end{tabular}

Note: $P_{c r}$ is the cracking load, $P_{u}$ is ultimate load, $P_{L / 250}$ is mid-span deflection value is $L / 250$ corresponding to the vertical load value, $D_{\mathrm{u}}$ is displacement corresponding to the ultimate load.

Another important parameter, the initial bending stiffness, defined as the secant rigidity of loaddisplacement curves from $0.1 P_{u}$ to $0.4 P_{u}$. Fig. 5 showed that the initial bending stiffness was improved by $13.1 \%$ with the presence of stiffeners. However, the bending stiffness decreased with the increase of shear span ratio.

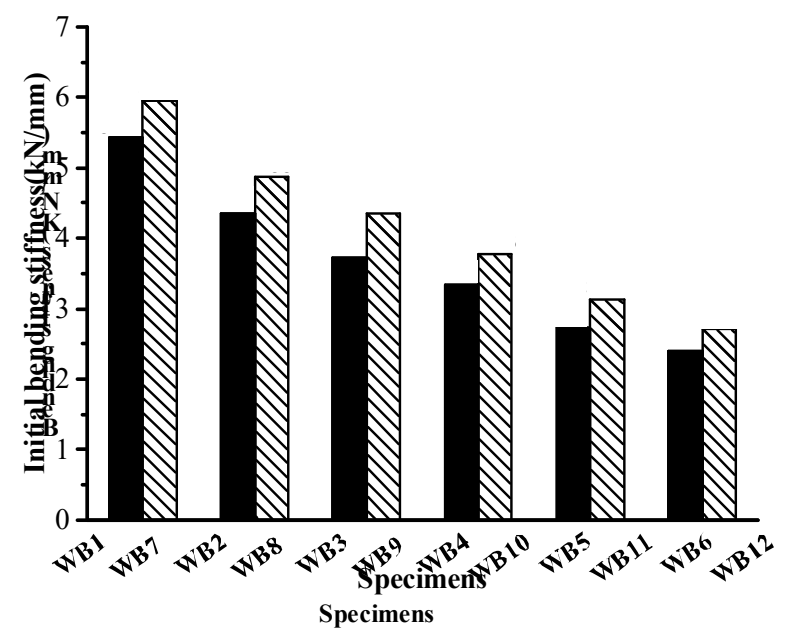

Fig.5. Bending stiffness.

\section{Acknowledgments}

This work was supported by the National Natural Science Foundation of China under Grant No.51408312, the Natural Science Foundation of Jiangsu Province under Grant No. BK20130982, College Students Practice and Innovation of Nanjing forestry university under Grant No. 201710298023Z, and the Priority Academic 
Program Development of Jiangsu Higher Education Institutions (PAPD), which are highly approciated.

\section{Conclusions}

The OSB webbed bamboo box shaped joists were introduced and tested, which could greatly increase the economic efficiency and promote the development of bamboo/wood structure. The following conclusions can be drawn:

Three failures modes were recorded, including web shear failure, local buckling of the web and delamiation of OSB panel from the flange, depending on the shear span ratio and stiffeners. Once reaching ultimate bearing capacity, the specimen lost its bearing capacity suddenly, showing brittle failure characteristics. The composite joists did not collapse or break into two parts, which was conducive to protect dwellers from injury or damage.

The load carrying capacity of composite joists at serviceability limit states was about $60 \%$ of the ultimate limit states. The load carrying capacity of beams decreased with the increase of shear span ratio. The ultimate bearing capacity and the initial bending stiffness were improved increased by $16.5 \%$ and $13.1 \%$ respectively with the present of stiffeners.

\section{References}

1. Y. Xiao, R. Z. Yang, B. Shan, Constr Build Mater, 44, 6 (2013)

2. H. T. Li, Q. S. Zhang, D. S. Huang, A. J. Deeks, Compos Part B-Eng, 54, 1 (2013)

3. F. Chen, J. Deng, H. Cheng, H. Li, Z. Jiang, G. Wang, J Wood Sci 60, 6 (2014)

4. D. Huang, Y. Bian, A. Zhou, B. Sheng, Constr Build Mater 77, 77 (2015)

5. H. T. Li, G. Wu, Q. S. Zhang, J. W. Su, J Wood Sci, 62, 6 (2016)

6. Y. Xiao, G. Chen, L. Feng, Mater Struct, 47, 11 (2014)

7. Y. Yu, X. Huang, W. Yu, Compos Part B-Eng 56, 1 (2014)

8. M. He, Z. Li, Y. Sun, R. Ma, Struct Des Tall Spec 24, 7 (2015)

9. Y. Li, W. Shan, H. Shen, Z. W. Zhang, J. Liu, Thin Wall Struct, 89 (2015)

10. Q. Xu, L. Chen, K. A. Harries, X. Li, Eur J Wood Wood Prod, 75, 2 (2017)

11. E. C. Zhu, Z. W. Guan, P. D. Rodd, D. J. Pope, J Struct Eng, 2006, 131, 10 (2005)

12. A. Sinha, D. Way, S. Mlasko, J Struct Eng, 140, 1 (2014)

13. E. C. Zhu, Z. W. Guan, D. J. Pope, P. D. Rodd, J Struct Eng, 133, 1 (2007)

14. M. T. Afzal, S. Lai, Y. H. Chui, G. Pirzada, Forest Prod J, 56, 10 (2006)
15. D. P. Hindman, J. R. Loferski, Practice Periodical on Structural Design and Construction, 13, 4 (2008)

16. R. W. Clinch, Forest Prod J, 43, 10 (1993)

17. T. Polocoser, T. H. Miller, R. Gupta, J Mater Civil Eng, 25, 12 (2013)

18. G. Chen, H. T. Li, T. Zhou, C. L. Li, Y. Q. Song, R. $\mathrm{Xu}$, Constr Build Mater, 101, (2015)

19. G. Chen, B. He, Bioresources, 12, 3 (2017)

20. Y. Xiao, Q. Zhou, B. Shan, J Bridge Eng, 15, 5 (2010)

21. W. Wu, J Bridge Eng, 19, 4 (2014)

22. M. Aschheim, L. M. Gil-MartíN, E. HernáNdezMontes, J Struct Eng, 136, 12 (2010) 